\title{
Differenz
}

Revista internacional de estudios heideggerianos y sus derivas contemporáneas

AÑO 6 NÚMERO 5: JULIO DE 2019. e-ISSN: 2386-4877 - DOI: 10.12795/DIFFERENZ.2019.I05.01

[pp. 11-27]

Recibido: 07/03/2019

Aceptado: 25/06/2019

\section{Donación y hogar mito-poético de la realidad}

\section{Donation and Mythopoeic Home of Reality}

\author{
Jon Mentxakatorre Odriozola \\ Universidad Autónoma de Madrid
}

\section{Resumen:}

Mediante selectos escritos de Heidegger sobre el vínculo entre poesía y verdad, se investigará cómo el lenguaje alberga al ser y cuáles son sus consecuencias. Para ello, se traerá a diálogo el pensamiento de Owen Barfield, pensador inglés contemporáneo a Heidegger interesado en la vía estético-epistemológica de la poesía. Sus aportaciones permitirán comprender el potencial de la palabra poética para saltar por sobre la dicotomía sujeto/objeto y mostrar cómo la poesía por la que Heidegger penaba es, ante todo, mitopoesía, porque la palabra capaz de acoger al ser, pensarlo en su misterio y desplegarlo en toda su hondura es mythos.

Palabras clave: Heidegger; Barfield; habla; palabra poética. 


\section{Abstract:}

Through selected writings by Heidegger on the link between poetry and truth, it will be investigated how language embraces the being and what its consequences are. To do so, the philosophy of Owen Barfield, an English thinker contemporary to Heidegger interested in the aesthetic-epistemological path of poetry will be brought into dialogue. His contributions will allow to understand the potential of the poetic word to jump over the subject/object dichotomy and to show how the poetry which Heidegger yearned for is, above all, myth-poetry, because the word able to welcome the being, to think about on its mystery and to unfold it in all its depth is mythos.

Keywords: Heidegger; Barfield; Speech; Poetic word.

Quien no sabe lo que es la nostalgia, tampoco sabe qué es filosofar Martin Heidegger

\section{Introducción ${ }^{1}$.}

En el pensamiento de Heidegger, uno de los más grandes pensadores del siglo XX, encontramos una premisa angular, desde la que muchas y poderosas propuestas filosóficas brotan: El ser es presencia, pero un halo de misterio lo envuelve, de forma que el ente toma primacía frente a él. En consecuencia, la metafísica ha pensado al ente como objeto, olvidando al ser que permite pensar(lo). Por lo tanto, para Heidegger, se hacía necesario pensarlo todo nuevamente: saltar por sobre los (post)idealismos y llegar al pensamiento que tenga presente al ser, que no lo obvie y caiga en el juego vicioso de subjetividad del sujeto y objetividad del objeto. Lo interesante en ese camino de Heidegger, tema de esta investigación, es el papel de la dicción poética, porque la razón, además de pensamiento, es habla².

El objetivo de este texto, a partir de escritos selectos de Heidegger sobre el vínculo entre poesía y verdad, es investigar cómo el lenguaje alberga al ser y cuáles son sus

$1 \mathrm{El}$ presente texto, que pone en diálogo a Heidegger y Barfield, surge para seguir y completar la vía de investigación abierta por la comunicación que puso en diálogo a Heidegger y Tolkien titulada "Palabra poética: la fundación del ser humano desde el lenguaje", presentada en la Universidad de Valladolid el 27 de septiembre de 2018, en el congreso Antropología y Comunicación, y publicada recientemente en Hombre y logos. Ed. J. M. Chillón, Á. Martínez y P. Frontela. Madrid, Fragua, 2019, 215-224.

2 Sobre la necesidad que Heidegger tuvo de dejar entrar al lenguaje y a la poesía en su filosofía, véase GADAMER, H.-G. Los caminos de Heidegger. Barcelona, Herder, 2002. 
consecuencias. Para ello, se traerá a diálogo el pensamiento de Owen Barfield, pensador inglés contemporáneo a Heidegger interesado en la vía estético-epistemológica de la poesía. Sus aportaciones permitirán comprender el potencial de la palabra poética para saltar por sobre la dicotomía sujeto/objeto y mostrar cómo la poesía por la que Heidegger penaba es, ante todo, mito-poesía, porque la palabra capaz de acoger al ser, pensarlo junto a su misterio y desplegarlo en toda su hondura, es mythos.

En primer lugar, se expondrá cómo el hablar poético es superior para Heidegger al hacer camino desde el que lo sobreabundante irrumpe en la realidad. Su diferencia del lenguaje actual abrirá la vía para comenzar a dialogar con Barfield, cuyos postulados se presentarán para indicar que el lenguaje poético es originalmente mítico, capaz de recoger la donación y sobreabundancia del ser. Posteriormente y junto algunas reflexiones desde el euskera, se explicará cómo al explorar la plurivocidad de la palabra poética, la riqueza del ser acogido en el lenguaje, pueden fundarse o sub-crearse, como nueva donación, los horizontes de sentido que conforman la base de un pueblo. Con todo ello se concluirá que la palabra poética que Heidegger reclamaba, es continente en sí misma de una participación de otro orden con la realidad, y que su capacidad reside precisamente en ser palabra que acoge el gratuito (don) ser y su misterio (sobreabundancia) tras el silencio (muthos) en su polisemia (verbum) que exige despliegue (narratio); es decir, la palabra poética es tal porque es mythos. Por esa razón, podremos afirmar que el camino para la metafísica querido por Heidegger no es otro que la mito-poética.

\section{Mythos y metáfora}

Pensando tras Hamman, Humboldt y Herder, Heidegger expuso que la razón es habla,

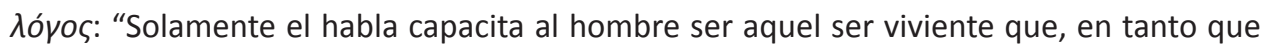
hombre, es. El hombre es hombre en tanto que hablante" ${ }^{3}$. Hablar y pensar son uno, pero separados por un abismo. Sin embargo, hay modo de salvarlo, pues el habla es, ante todo, dar nombre. Al nombrar, al acoger en el lenguaje, se in-voca, in-venta, se trae a voz presente lo apelado y al mundo perteneciente en el que toma sentido. Nombrar, en consecuencia, es poíesis. A partir de los primeros versos del poema 'Una tarde de invierno' (Ein Winterabend, 1915) de Georg Trakl, Heidegger expuso lo siguiente:

Wenn der Schnee ans Fenster fällt, Lang die Abendglocke läutet ${ }^{4}$

3 HEIDEGGER, M. "El habla”, en De camino al habla. Barcelona, Serbal-Guitard, 1990. p. 11. 4 Cuando cae la nieve en la ventana / Largamente la campana de la tarde suena. 


\begin{abstract}
¿Qué es este "nombrar"? ¿Rodea solamente con palabras de una lengua a los objetos y sucesos conocidos y representables: nieve, campana, ventana, caer, resonar? No. El nombrar no distribuye títulos, no emplea palabras, sino que llama las cosas a la palabra. El nombrar invoca (...) trae a cercanía la presencia de lo que anteriormente no había sido llamado (...) Pero la invocación no arranca a lo que está siendo llamado a su lejanía en la que permanece retenido por el "hacia dónde" del llamado. La invocación invoca en sí y, por ello, llama hacia aquí, hacia la presencia y llama hacia allá, en la ausencia. La nieve que cae y la campana de la tarde que suena nos está siendo dicho aquí y ahora por el poema. Llegan a presencia de la invocación. Pero no toman su lugar en medio de lo que es aquí ahora presente en esta sala. ¿Cuál es más alta: la presencia que tenemos ante nuestros ojos o la presencia invocada? ${ }^{5}$
\end{abstract}

Acorde a Heidegger, invocar es llamar a proximidad, hacer venir a lo nombrado y al mundo al que pertenece, pues al dar, al decir, nombre tanto el elemento como la realidad de la que toma sentido son traídas. Lo nombrado se presenta en este mundo como mundo secundario, que si es poderoso, coherente en sí, permite entrar en él y después ligarlo a este mundo: funciona como metáfora "desde" lo lejano, en vez de "a" lo lejano. Ahora bien, ha de comenzarse a notar que este tipo de nombrar es el que hace el mito, que guarda en sí no un elemento concreto, sino toda una experiencia, todo un mundo, que se llama a despliegue. Y no solo eso: enlaza la realidad presente al conjunto diegético del mito, por lo que la historia sigue siendo la misma historia que se dijera la primera vez. De ahí que Heidegger llegara a plantear que la realidad que irrumpe mediante el nombrar del poeta es superior, de mayor talante, y que abre la posibilidad de ser metáfora, de sobreponerse a la realidad presente y dotarla de sentido que ha acompañado a toda una historia de la cultura, de seguir haciéndola partícipe de una misma palabra y voto ${ }^{6}$. El (verdadero) nombrar, por lo tanto, es siempre poético para Heidegger. Sin embargo, según el filósofo, este escasea:

El hablar de los mortales es invocación que nombra, que encomienda venir cosas y mundo desde la simplicidad de la Diferencia. Lo que es hablado en el poema es la pureza de la invocación del hablar humano. Poesía,

5 HEIDEGGER, M. “El habla”. Cit. p. 19.

6 "La invocación que llama cosas llama a venir, las invita a la vez que llama hacia ellas, las encomienda al mundo desde el cual hacen su aparición" (Ib. p. 20). Aceptar que las cosas son primero llamadas a su propio mundo implica que existe más mundo previa e independientemente del conocimiento humano sobre él. 
propiamente dicho, no es nunca meramente un modo (Melos) más elevado del habla cotidiana. Al contrario, es más bien el hablar cotidiano un poema olvidado y agotado por el desgaste y del cual apenas ya se deja oír invocación alguna.

Lo contrario a lo hablado puro, es decir al poema, no es la prosa. La prosa pura no es jamás "prosaica". Es tan poética y por ello tan escasa como la poesía?.

Es decir, el habla, el poetizar, ha devenido lenguaje ordinario para Heidegger, olvidando -ocultando, recordando a Trías- la fuerza del nombrar. De forma similar, para Barfield, el lenguaje ha ido perdiendo capacidad para abarcar la experiencia en unidad, debido no tanto a la abstracción y lógica como a la introspección individual, egocéntrica y consciente. ¿En qué consiste, por lo tanto, el nombrar que Heidegger reclamaba? ¿Cómo recuperarlo? Para ello, será revelador atender a los postulados de Barfield en cuanto a la relación de la poesía para con la verdad.

\subsection{Nombrar participativo}

Heidegger dice que la poesía es el lenguaje que salva la distancia entre habla y pensamiento. En ello reside su capacidad para instaurar el ser y la esencia de la realidad, en responder a su altura, en hacer sitio, albergar, cobijar, la realidad -aísthesis, en toda regla-, mostrándola, iluminándola, desde sí. De ese modo la palabra es patria: ha creado un mundo -de todos los posibles- de la realidad, y vive a partir de ella. Nombrar, por lo tanto, no es vano, relativo o caprichoso: es certero, acorde, parejo. El pensar, el discurrir, se hace mediante el habla, pero una vez dicho el mundo poéticamente. Porque solo la poesía es capaz de decir el ser, de trascender el ente y fundar el entramado de sentido que forma una cosmovisión y cultura ${ }^{8}$. Tal como dice Barfield:

Logic can make us more precisely aware of the meaning already implicit in words. But the meaning must first of all be there and, if it is there, it will always be found to have been deposited or imparted by the poetic activity 9 .

\section{7 lb. p. 28.}

8 "La poesía no toma el lenguaje como un material existente, sino que la poesía misma hace posible el lenguaje. La poesía es el lenguaje primitivo de un pueblo histórico (...) es preciso entender la esencia del lenguaje por la esencia de la poesía" (HEIDEGGER, M. Arte y poesía. México DF, FCE, 1985. p. 140). Es decir, Heidegger se sitúa, junto a Barfield, en que el lenguaje actual proviene del poético primordial: aún guarda su eco (Ib. p. 114).

9 BARFIELD, O. Poetic Diction. A Study in Meaning. Middletown, Wesleyan UP, 1973. p. 31. 
Sin embargo, cuando el nombrar poético pierde su fuerza y deviene en lenguaje ordinario o técnico, el ser desaparece u oculta en el ente, porque ha perdido sus relaciones de sentido que lo hacen mostrarse en la verdad. Cuando tal cosa ocurre, la metáfora puede salvar la situación.

En Poetic Diction, tras afirmar que la metáfora, al recorrer la antigua senda poética, es el único camino hacia el conocimiento, Barfield se centra en el problema del lenguaje mismo, llamando a discurso para rebatir la visión lingüística avanzada por algunos filólogos del siglo XIX, Max Müller a la cabeza. Aquellos estudiosos creían que la metáfora había surgido en acto imaginativo consciente por parte de un individuo que, con el objetivo de expresar algo abstracto a otros, toma palabras a mano y les da nuevo significado. La necesidad de la metáfora aparece ligada a la literalidad de las palabras, utilizadas para expresar objetos o hechos físicos concretos; algo abstracto habría de pedir nuevos sentidos.

El argumento decimonónico proviene del traspaso del evolucionismo de Darwin a la historia del lenguaje, y no desde la evidencia lingüística. En el contexto del desarrollo físico y mental del hombre primitivo hasta el ser humano moderno, se entendía que la capacidad de abstracción había de venir en un estado evolutivo posterior. En consecuencia, las primeras palabras habrían de ser herramientas concebidas al modo de los materiales: de uso directo. Estas designarían objetos unívocamente y por conveniencia bajo este supuesto, y una capacidad mayor para la abstracción llegaría después mediante la ingeniosa combinación de esas palabras, gracias a la metáfora ${ }^{10}$. Pero tal como Barfield resalta, dentro de límites lingüísticos, la realidad es otra, pues el lenguaje, cuanto más remoto, más metafórico es, en el sentido de que las antiguas palabras nunca hablan "solamente" de un objeto o hecho físico, sino de un pensamiento y percepción en el que visible e invisible, externo e interno, se nombran en unidad. Al respecto, tratando de las palabras diurnal, diary, dial y journal, derivadas de la latina dies, Barfield dijo así:

As far back as we can trace them, the Sanskrit word "dyaus", the Greek "zeus" (accusative "dia") and the Teutonic "tiu" were all used in contexts where we should use the word sky; but the same words were also used to mean God, the Supreme Being, the Father of all the other gods -Sanskrit "Dyaus pitar", Greek "Zeus pater", Illyrian “Deipaturos", Latin "Juppiter" (old

10 Sería cuestión de tiempo que Saussure comenzara a dictar sus cursos: las bases estaban asentadas para la división entre significante y significado, y para definir al hombre moderno. Tal como dice McLuhan: "Con el signo sin sentido asociado al sonido sin sentido, hemos construido la forma y el sentido del hombre occidental". MCLUHAN, M. La galaxia Gutenberg: Génesis del homo typographicus. Barcelona, Galaxia Gutenberg, 1998. p. 77. 
form "Diespiter"). We can best understand what this means if we consider how the English word heaven and the French "ciel" are still used for a similar double purpose, and how it was once not a double purpose at all. There are still English and French people for whom the spiritual "heaven" is identical with the visible sky; and in the Spanish language it is even a matter of some difficulty to draw the distinction. But if we are to judge from language, we must assume that when our earliest ancestors looked up to the blue vault they felt that they saw not merely a place, whether heavenly or earthly, but the bodily vesture, as it were, of a living Being. And this fact is still extant in the formal resemblance between such words as diary and divine ${ }^{11}$.

Barfield apunta que el antiguo lenguaje conocido muestra una conciencia que no distingue entre literal y figurado. La distinción de metáforas y conceptos vendría después, con el cambio de participación en unidad en el mundo, con el paso del pensamiento mítico al filosófico-científico. En consecuencia, el giro en la percepción del puesto del hombre en el cosmos deja en claro que, en los albores del tiempo, el lenguaje era, originalmente, mito, así como que el lenguaje ha ido convirtiéndose más prosaico ${ }^{12}$. Al respecto, es interesante que, en este proceso, Barfield encuentra un importante punto de inflexión: un encuentro y nombramiento del mundo interior de la conciencia, distanciándose de una participación directa en la realidad, en el sentido griego de "pánico"13: empieza a mostrarse el cambio que se producirá, desde la conciencia de un agente divino externo (Pan), al mundo mental y analítico interior -y a la muestra de cómo el mito ha quedado desfigurado pero vivo en el habla cotidiana. La mente, en su mayor grado de abstracción, encuentra a la realidad menos real; cuanto más interior es el mundo, más abstracto es. Para Barfield, por lo tanto, queda claro que en los albores del tiempo, el lenguaje era, ante todo, mito:

As to the number of words which are indirectly descended from the prehistorical religious feeling, it is not possible to count them. We can only

11 BARFIELD, O. History in English Words. Barrington, Lindisfarne Books, 2007. p. 88-89.

12 Cassirer, en diálogo con la obra de Usener, aunque concluye que el origen del mito y el del lenguaje son análogos, sostiene que mythos y logos brotan del pensamiento humano desde el principio (CASSIRER, E. Mito y lenguaje. Buenos Aires, Galatea, 1959. p. 82-83, 96; CASSIRER, E. Antropología filosófica. Introducción a una filosofía de la cultura. México D.F., FCE, 1974. p. 166). De ahí que insista en que el hombre y su lenguaje -tanto figurativo como abstracto- son creativos en tanto que "simbólicos" (Ib. p. 197), sin incidir en que son, sobre todo, y en mayor medida cuanto más antaño, fundacionales, "poéticos". La palabra poética no niega una complementación o bifurcación, o dos modos de pensar y de expresar mediante el lenguaje coetáneos desde el principio, sino que resalta la capacidad de nombrar la realidad en la medida en que se presenta.

13 BARFIELD, O. History in English Words. cit. p. 85-87. 
say that the farther back language as a whole is traced, the more poetical and animated do its sources appear, until it seems at last to dissolve into a kind of mist of myth ${ }^{14}$.

Es decir, Barfield sostiene que las palabras hubieron de tener antiguamente en unidad múltiples significados, o dicho de otro modo, hubieron de tener un único significado, y varios fenómenos referentes al mismo tiempo -sin distinción-, tanto externos como internos, tanto mentales como materiales. La tendencia del lenguaje hasta hoy ha sido concretar y clarificar esos significados: la división de unidad semántica mediante selección. Así, como ejemplo, mientras que Müller habría dicho que "espíritu" habría significado "aliento" o "viento", y que después llegaría la necesidad de expresar la abstracta noción de "el principio de vida", Barfield expone lo siguiente:

Such an hypothesis is contrary to every indication presented by the study of the history of meaning; which assures us definitely that such a purely material content as "wind", on the one hand, and on the other, such a purely abstract content as "the principle of life within man or animal" are both late arrivals in human consciousness. Their abstractness and their simplicity are alike evidence of long ages of intellectual evolution. So far from the psychic meaning of "spiritus" having arisen because someone had the abstract idea, "principle of life..." and wanted a word for it, the abstract idea "principle of life" is itself a product of the old concrete meaning "spiritus", which contained within itself the germs of both later significations. We must, therefore, imagine a time when "spiritus" or $\pi v \varepsilon v \mu \alpha$, or older words from which these had descended, meant neither breath, nor wind, nor spirit, nor yet all three of these things, but when they simply had their own old peculiar meaning, which has since, in the course of evolution of consciousness, crystallized into the three meanings specified -and no doubt into others also, for which separate words had already been found by Greek and Roman times ${ }^{15}$ (1973: 80-81).

Es decir, lo que a día de hoy parece ser metáfora es sentido que estaba latente desde el principio. Las antiguas palabras no designaban solo algo sensible o material, sino que lo designaban conjuntamente, porque aún no distinguían a uno del otro. Tal diferencia entre objetivo-subjetivo supondría conciencia de sí mismo que trabaja con pensamiento

14 lb. p. 88-89. Véase también CASSIRER, E. Mito y lenguaje. cit p. 82-83, en donde expone la dificultad del lenguaje para hablar del ego y del ser, así como su tardía concepción.

15 BARFIELD, O. Poetic Diction. A Study in Meaning. cit. p. 80-81 
racional o discursivo sobre ideas abstractas ${ }^{16}$, que se desarrolló en un tiempo y lugar concreto: Ática, en el siglo V. De modo que exigir tanto la literalidad como la metáfora al antiguo lenguaje mítico, o como Barfield dice, volcar el pensamiento poslógico en el prelógico, supone un ejercicio de logomorfismo ${ }^{17}$. Por lo tanto, en aquel tiempo prelógico, el tiempo en el que el sentido se originaba, el hombre no se sentía distinto o sacado del universo, al menos no tanto como después de Platón: participaba como parte de él. Ligándolo a Heidegger, el nombrar, al igual que la pregunta filosófica, envolvía al hablante. Porque este también escucha, forma parte de la misma audición y acontecimiento.

\subsection{Vía al nombrar original}

Lo expuesto hasta ahora nos indica lo siguiente: En un tiempo primigenio no existía distinción entre sujeto y mundo, entre pensar y percibir; ha sido el cambio de conciencia respecto a la presencia del mundo la que ha llevado a separar puntos interpretativos de experiencia. En consecuencia, Barfield describe el antiguo modo de pensamiento como:

A kind of thinking which is at the same time perceiving -a picture-thinking, a figurative, or imaginative, consciousness, which we can only grasp today by true analogy with the imagery of our poets, and, to some extent, with our own dreams ${ }^{18}$.

Por ello, la historia que queda en el lenguaje, investigable mediante la filología, muestra, junto al cambio de la conciencia humana, dos principios opuestos del lenguaje mismo. El primero es que el antiguo único sentido tiende a dividirse, especificarse. El segundo, la naturaleza misma del lenguaje, es el principio de la unidad viva. Mientras que el primero indica diferencias, el segundo muestra las semejanzas, encuentra y funda una base común. Y dicho segundo principio es el que opera en la metáfora, que trata de decir la realidad en unidad.

Mediante la metáfora, el poeta logra transmitir relaciones perdidas, olvidadas o desconocidas, que no hallan otro modo de expresión sino por ella. A su vera, la poesía se vuelve vía para experimentar la realidad en evidencia, en totalidad, o para abrir el camino a ello. Mientras que el ejercicio intelectual busca reducirse conceptualmente y especificarse

16 "A subjective -or self- consciousness is inseparable, as Kant himself demonstrated quite satisfactorily, from rational or discursive thought operating in abstract ideas. Consequently, in prelogical times it could not have existed at all". Ib. p. 204.

17 lb. p. 90; 187.

18 lb. p. 206-207. 
en sus partes, alejándose del conocimiento participativo, el pensamiento poético funda las bases para reunir al hombre con la realidad y llegar a mayor comprensión de ella.

Recogiendo uno de los ejemplos dado anteriormente: en la actualidad, al traducir spiritus, necesitamos verterla dependiendo del contexto como -y solamente como"espíritu", "aliento", "vida" o "viento"; se se(le)cciona un significado. Para el pensamiento mítico, la palabra daba respuesta a una experiencia multidimensional: el "espíritu-alientovida-viento". Además, la antigua palabra encontraba su forma narrativa, su despliegue, en el relato -el mito o cuento mítico. El mito, por lo tanto, es la palabra que contiene en sí una infinidad de despliegue diegético: el verbum es esencialmente narratio; en una sola palabra: mythos.

Así pues, la poesía, ejercida continuamente, es la que otorgaría un conocimiento cada vez mayor, porque es la metáfora la que se acerca a expresar la antigua unidad semántica, la antigua unidad entre pensamiento y percepción que se llevó al habla y que el lenguaje muestra tanto en viejas expresiones como "el sol se ha puesto" o nuevas como "agujero negro" o "trolear".

Resumiendo brevemente lo dicho en este apartado: Barfield llegó a la conclusión de que la sentencia de Müller -la mitología (mito-poética) como enfermedad del lenguaje ${ }^{19}$ era falsa, al sostener que el mito está estrechamente relacionado con el origen del habla y la literatura, y no como posterior decorado de lo literal. En aquella fase comentada, en la que lo literal no se distinguía de lo metafórico, tanto las palabras como el pensamiento eran de orden mítico, nombrando en unidad distintas dimensiones de la realidad. No obstante, debido a la tendencia del ejercicio analítico-conceptual, la riqueza poética original de las antiguas lenguas ha decaído a lo largo de los siglos hasta los actuales idiomas modernos, cuyo alto grado de abstracción y concreción les priva de la potencia para llamar mundos de experiencia estético-semántica mediante el nombre. Sin embargo, le metáfora tiende la vía para llegar al núcleo original20.

Ahora bien, tal como Heidegger comprendía, la perspectiva de la historia que la metafísica legó se excusa en que el misterio acompaña al ser, haciéndolo difícil de asir. Hablando en clave mito-poética, la realidad presenciada como don es excesiva,

19 Véase al respecto el breve comentario de Cassirer. (Antropología filosófica. Introducción a una filosofía de la cultura. cit. p. 166-168). Tal como dice el autor, no es adecuado llamar enfermedad a una actividad fundamental del ser humano.

20 Del pensamiento de Barfield podemos derivar lo siguiente: como no despertamos por primera vez, porque nacemos ya a un pueblo y heredamos lenguaje, como no nombramos la realidad por primera vez, la vía más accesible es la metáfora, tendiendo puentes entre seres o sentidos que antiguamente el lenguaje decía en unidad. 
sobreabundante de sentido y ser, y el lenguaje, en su flaqueza entre lo literal y lo metafórico, divaga en cómo poder dar cuenta de él ${ }^{21}$. Pero en ese silencio, en esa mudez, entra en juego la palabra poética, que como veremos no es otra que mito. El primer paso, es darse cuenta de formar parte de una realidad maravillosa, asombrosa aunque terrible: saberse parte de ella. El segundo, decirla: recoger toda la vivencia en la palabra poética y hacer partícipes de esa vivencia mediante el arte narrativo a otras personas, invitarlos, mediante la imaginación compartida, a vivir el mito por ellos mismos, por encuentro con o aplicación de su sentido, contar la multiplicidad de sentido recogida en el mythos y crear, fundar, el mundo con las coordenadas de esa experiencia, con los horizontes de sentido al que volcar el pensamiento.

Es decir, el verdadero nombrar es capaz de recoger en abundante unidad toda una experiencia estético-semántica. Pero algo es necesario para ello: percibir el ser como don y como sobreabundante. Solo al tener presente su gratuidad y riqueza puede mantenerse el diálogo al que llama, sin limitar u obviar su maravilla o misterio. De ese modo, el ser puede ser acogido en su acontecer, arrojarse a la relación con otros seres. En consecuencia, al albergar en la palabra el ser y sus puntos de convergencia, el ser humano es en tanto que construye mundos de sentido desde el lenguaje. Con la dicción de la realidad en toda su hondura, la poesía es capaz de fundar la realidad porque sale a su encuentro para des-ocultarla, mediante la alétheia de la palabra. No impone idea o teoría unívoca alguna sobre el ente, sino que, con asombro y reverencia, al percibir al ser como don radical y exuberante, lo acoge en unidad y en relación para con otros seres. Tal como dice Eagleton:

El Ser, por lo tanto, es ese "claro" (Lichtung) o espacio de encuentro que no es ni sujeto ni objeto sino, de algún modo, la disponibilidad espontánea de uno hacia otro (...) Dado que es en primera instancia un ser-en-el-mundo, es una forma de existencia inexorablemente referida a otras cosas, y es a través de esta ligazón a las cosas como conduce a estas a su autorrevelación ${ }^{22}$.

Esas palabras sobre el pensamiento de Heidegger son muy significativas, porque hallamos en ellas el punto de apoyo para mostrar una vez más su similitud de trasfondo con el pensamiento de Barfield, quien insiste en la no distinción entre sujeto y objeto en la conciencia y lenguaje de antaño. El ser, por lo tanto, se presenta en esa unidad porque se da en totalidad a los demás seres: está dado, está llamado, se arroja, a la relación con

21 "Pero reflexiónese sobre el hecho de que el giro, que también aparece en el habla cotidiana, 'me faltan las palabras' -es decir, 'me quedo mudo'- en realidad quiere decir que a uno le sale al encuentro algo sorprendente e inesperado y que faltan las expresiones justas para decir lo que hay que decir" (GAdAMER, H-G. Mito y razón. Barcelona, Paidós, 1997. p. 112).

22 eAgleton, T. La estética como ideología. Madrid, Trotta, 2006. 
otros seres. Y esas relaciones, tras las cuales se haya la verdad de la realidad, existen independientemente del conocimiento humano de ellas. De igual manera, el verdadero conocimiento de la realidad consiste en fundarla: llamar, decir, poéticamente las relaciones encontradas estéticamente, para tras traer el ser al habla, volcar el pensamiento y la razón sobre tal decir. La poesía cobija la realidad, la razón estudia lo albergado. Pero sin poesía, no solo el pensamiento no haya sus límites, sino que el ser humano, en tanto que ser, no tiene posibilidad de fundar su relación para con otros seres. Al quedar fuera de la realidad, la realidad yace separada de él.

De modo que el logos poético sale al encuentro de la realidad para des-velarla, llevarla al habla y dotar al hombre de mundos de significado. La poesía es, por lo tanto, la que dice el ser y hace cosmos, la que encuentra y recoge de manera única lo que ya está dado, presentado. El lenguaje, la cultura... son solo posibles tras la poesía. De ahí que el habla, el lenguaje, sea para Heidegger posible comprenderlo tras entender el habla poética; y solo tras comprender el habla poética se entiende el ser. Ahora se entiende su clave: "La poesía es instauración del ser con la palabra"23. Cuando pensar el ser se basa en decir (poetizar) el ser, nombrar es el supremo conocimiento.

\section{Habitar poéticamente}

Tal como Gadamer recordara de Heidegger, pensar desde la traducción latina animal rationale ha conducido a la filosofía a tomar al hombre como ser racional, cuando pensar desde el original griego aristotélico zōon logon echon conduce, con mayor sensibilidad, a tomar al hombre como ser de palabra: es el lenguaje el que hace al hombre ser humano, porque es en la palabra donde se muestra y donde comulga con lo(s) demás ${ }^{24}$. Por esa razón, antes de tomar el lenguaje como sistema codificado de comunicación o estudio conceptual, algo previo aflora: el lenguaje como arte, como elemento de "comunión", de "comunidad", pues es la palabra "poética" la que llama al ser a la realidad y la que sitúa al hombre en diálogo con ella, como criatura que construye mundo hilando entre seres un entramado de sentido donde la realidad se muestra en su verdad:

El habla no es solo ni primeramente una expresión oral y escrita de lo que debe ser comunicado (...) Cuando el habla nombra por primera vez al ente, lo lleva a la palabra y a la manifestación (...) La Poesía es el decir de la desocultación del ente (...) En tal decir se acuñan de antemano los

23 HEIDEGGER, M. Arte y poesía. cit. p. 137.

24 GADAMER, H-G. Mito y razón. cit. p. 73. 
conceptos de la esencia de un pueblo histórico, es decir, la pertenencia de este a la historia universal ${ }^{25}$ (Heidegger, 1985: 112-113).

\subsection{Prístina mirada}

Cuando el hombre despierta, lo primero que en silencio percibe y es acogido en el lenguaje se vuelve fundamento del ser. Aquello a lo que se da nombre por primera vez se vuelve base sobre la que edificar la existencia, tal como la luz de las estrellas sobre el agua. En ese momento se consolida la relación entre lengua y mitología, en el momento en el que se descubre la creación y se acoge el ser sobre el que se conlleva la construcción de un pueblo. En euskera, por ejemplo, izar (estrella) ofrece el verbo izar(tu) (despertar), después de surgir de iz (luz), que a su vez es origen de toda (h)i(t)z (palabra). De modo que el lenguaje erige una forma de ser y dimensión mitológica desde la raíz. Ahí reside su intrínseca relación. Lo que la mitología nutre y siembra en los corazones es precisamente lo que siempre peligra: la fuente misma tanto del ser como de la lengua.

Tal como venimos diciendo, ese hablar mítico es el que en el pensamiento de Heidegger es poesía. La palabra, ante todo, es poética: el ser humano, desde el origen, habita poéticamente este mundo; desde el decir primordial y desde las metáforas que se elevan desde el lenguaje ordinario.
"Habitar poéticamente" significa estar en la presencia de los dioses y ser tocado por la esencia cercana de las cosas. Que la existencia es "poética" en su fundamento quiere decir, igualmente, que el estar instaurada (fundamentada) no es un mérito, sino una donación ${ }^{26}$.

Al despertar, todo es absolutamente asombroso, tanto lo bello como lo oscuro. El ser humano se sabe ante una realidad múltiple, abundante y que le es ajena: no la ha pensado, pero está para él. La luz de las estrellas en la noche, los rayos de sol por el día... todo es regalo para su habitación. Mediante el habla, sustentado sobre tal ser dado y por lo tanto dado por esa realidad, es capaz de empezar un hogar. Su existencia, en toda vertiente, es don: respuesta a la llamada a instaurarse sobre fundamento dado. Al decir de Heidegger, la poesía es instauración del ser por la palabra porque:

Al ser nombrados los dioses originalmente y llegar a la palabra la esencia de las cosas, para que por primera vez brillen, al acontecer esto, la existencia

25 HEIDEGGER, M. Arte y poesía. cit. p. 112-113.

26 Ib. p. 139. 
del hombre adquiere una relación firme y se establece en una razón de ser. Lo que dicen los poetas es instauración, no solo en sentido de donación libre, sino a la vez en sentido de firme fundamentación de la existencia humana en su razón de $\operatorname{ser}^{27}$.

De modo que la poesía, al trascender la expresión personal y ser compartida, otorga un componente epistémico y social, al ser vehículo de transmisión de memoria, imaginación e historias. La función del poeta siempre ha sido mantener ese núcleo de elementos vivo, hacer presentes los secretos del mundo. Podríamos decir, por lo tanto, que vox poetae, vox populi, dado que el poeta es aquel que recuerda el camino de los mayores, el que crea sentido a partir de ello: es el sabio, el que conoce lo que subyace a los refranes y el que sabe cómo se gira una historia. Heidegger responde así a la pregunta abierta por Platón: el poeta conoce íntimamente aquello de lo que habla; más bien, es el único que lo conoce. De ahí que se lo considere el medium, el medicus, entre lo divino y el pueblo, y hace de esta tierra hogar por la poesía: “El poeta mismo está entre aquellos, los dioses, y este, el pueblo" 28 .

De modo que los Dioses, al llamar al hombre, le han dado existencia y habla. El tema yace desde entonces en el diálogo para con ellos ${ }^{29}$, y para eso hacemos patente otra palabra original: e(ra)ntzun. En euskera, "oír", "escuchar", "atender" y, sobre todo, "aprehender", es entzun. Y su factitivo, "enseñar a oír, escuchar, atender, aprehender", "hacer oír, escuchar, atender, aprehender", es erantzun, literalmente, "responder". La forma de entzun -su comienzo vocal, raíz y participio, así como su adopción de -ra- como interfijo- nos muestra que es un verbo antiguo, sobre el que se sustenta la razón del habla: el dialogo.

\subsection{Donación}

Lo que pensar en euskera ilumina es que la mejor manera de responder es escuchando a la altura de las circunstancias, que antes de la palabra están el silencio y la apertura: o mejor,

27 Ib. p. 138.

28 Ib. p. 144.

29 "Pero a la palabra poética no le tocaría su fuerza nominativa, si los dioses mismos no nos dieran el habla". Ib. "Pero los dioses solo pueden venir a la palabra cuando ellos mismos nos invocan, y estamos bajo su invocación. La palabra que nombra a los dioses es siempre una respuesta a tal invocación. Esta respuesta brota, cada vez, de la responsabilidad de un destino. Cuando los dioses traen al habla nuestra existencia, entramos al dominio donde se decide si nos prometemos a los dioses o nos negamos a ellos". Ib. p. 136. 
que el silencio es la verdadera palabra, que la mejor palabra es aquella que dice al son del silencio; es decir, una vez más, muthos (mythos). Porque el diálogo, la escucha y respuesta como re-escucha, extendida en la Historia, es lo que hace hombres. Es ahí, al no degradar el habla, que el hombre sabe que no es criatura, sino Criatura, llamada a participar en la realidad. Al olvidar el verdadero habla, cuando el racionalismo ha destruido la maravilla y el diá-logo con el Lógos, la realidad vuelve a ocultarse: es siniestra, absoluta, y el ser desaparece en el ente. En consecuencia, se vuelve a estudiar meticulosamente a este, para quitar capas de cebolla y no hallar su ser.

La más elevada capacidad -o posibilidad- de ser hombre está en el habla, en el hogar que hay en la palabra. Poetizar, instaurar la realidad, es dotar a una gente de las piedras angulares de las arquitecturas y esculturas de su tierra: la fundación de un mundo. La poesía, por lo tanto, es trascendente, intachable -aunque posible de olvidarse en el lenguaje mediante la degradación de este: es suprahistórica. Porque toda realidad histórica, toda cultura, es también sub-creación, y por lo tanto, un recoger la verdad en la medida en que esta se presenta donada, libre de la cadena experiencial de causa-efecto. Al respecto, son interesantes las siguientes palabras de Heidegger:

El arte como poner-en-obra-la-verdad es Poesía (...) El poner-en-la-obra la verdad impulsa lo extraordinario a la vez que expulsa lo habitual y lo que se tiene por tal. La verdad que se abre en la obra nunca se deduce ni se comprueba por lo hasta ahora ocurrido. Esto en su exclusiva realidad queda anulado por la obra. Por eso lo que el arte instaura nunca se compensa ni se suple con lo existente disponible. La instauración es una superabundancia, una ofrenda ${ }^{30}$.

En palabras del propio Heidegger tenemos que el verdadero arte es Poesía, que esta es nueva y verdadera, que es fruto y causa de asombro y contemplación, que responde a la sobreabundancia y que es don. Por ello Heidegger dirá que el obrar del artista es sacar, extraer (schöpfen), y no creación absoluta:

El subjetivismo moderno entiende mal lo creador en el sentido de la tarea genial del sujeto soberano. La instauración de la verdad no es solo instauración en el sentido del libre ofrecimiento, sino a la vez instauración en el sentido de fundamento que funda. La proyección poética sale de la nada, en cuanto a que nunca toma su ofrenda de lo corriente y ya ahora ocurrido. Sin embargo, no sale jamás de la nada debido a que lo proyectado

30 lb. p. 114-115. Ramos nos advierte de una insuficiencia castellana para con la exposición de Heidegger, quien utiliza Dichtung y Poesie, y que traduce, respectivamente, Poesía y poesía. 
por ella solo es el destino mismo ya previamente contenido del existente histórico mismo (Dasein) ${ }^{31}$.

Es decir, el arte parte de lo conocido y liberado al artista en este mundo para traerle a lo mundano aquello que encuentra en su profundidad, de ahí que llamemos a su obrar y a su obra sub-creación. El arte, esencialmente el decir poético, hace eco de la llamada del ser, lo llama a ser, y permite a un pueblo encontrar su lugar en la historia mediante su modo particular de encauzar verdad suprahistórica. La poesía, por lo tanto, es el habla que funda el habla, aquel que acoge la realidad desde una perspectiva única y la hace habitable. Y es don: la poesía misma es recepción gratuita de una ofrenda, gesto irrepetible, que guarda todo un mundo de verdad como respuesta de experiencia estético-semántica.

\section{Conclusión: mito-poética}

Tras todo lo dicho, al recoger las aportaciones de Heidegger sobre el habla, el arte y la poesía y ponerlas en diálogo con las de Barfield, hemos de concluir y afirmar que la palabra poética, sub-creadora, la que funda los horizontes de sentido al salvar la distancia entre pensamiento y habla, es mythos. Porque la realidad percibida como sobreabundante y asombrosa donación que es llevada al habla necesita de la palabra que atiende en silencio a la maravilla o misterio (muthos), recoge en unidad su multidimensional hondura (verbum), y porque de tal palabra se despliegan los marcos narrativos en los que su potencia semántica encuentra la coherencia de sentido donde poder decir la verdad de forma única (narratio). El mythos, por lo tanto, es conciencia participativa, palabra y despliegue: poesía que llena el habla y une el pensamiento del hombre con la realidad.

Cuando una experiencia de mundo plural es abarcada por la palabra poética, necesita de la extensión del relato o poema: el mito se vuelve horizonte, dicción que crea lazos, comunidad. Brevemente dicho, el mito es la palabra en diálogo con la realidad, porque es primero silencio y respuesta correspondiente a su altura después. La plurivocidad del poema reside en la honda dimensión del mito, que no reduce el ser, que es ante todo acontecimiento gratuito, al contarlo en todas sus vertientes y significados. Solo así se da cuenta de la sobreabundancia del ser que se dona en su presencia. Es decir, la palabra poética es sub-creadora porque en el silencio y asombro ante el mundo envuelve el ser donado en su presencia, para fundar la realidad y desplegarla. Por eso podemos decir que la palabra poética que Heidegger destacaba en su pensamiento es en realidad mythos, y que la poética que asentara la vía para la metafísica que quería es en verdad mito-poética.

31 lb. p. 116. 
Con ello, se abre la vía a repensar el interés de Heidegger por la obra de poetas como Novalis, Hölderlin o Rilke, y estas como mito(s).

\section{Bibliografía}

BARfIELD, O. Poetic Diction. A Study in Meaning. Middletown, Wesleyan UP, 1973.

BARFIELD, O. History in English Words. Barrington, Lindisfarne Books, 2007.

CASSIRER, E. Mito y lenguaje. Tr. C. Balzer. Buenos Aires, Galatea, 1959.

CASSIRER, E. Antropología filosófica. Introducción a una filosofía de la cultura. Tr. E. Imaz. México D.F:, FCE, 1974.

EAgleton, T. La estética como ideología. Tr. G. Cano y J. Cano. Madrid, Trotta, 2006.

GADAMER, H-G. Mito y razón. Tr. J. F. Zúñiga García. Barcelona: Paidós, 1997.

gAdAMER, H-G. Los caminos de Heidegger. Tr. A. Ackermann. Barcelona: Herder, 2002.

HEIDEGGER, M. Arte y poesía. Tr. S. Ramos. México D.F., FCE, 1985.

HEIDEGGER, M. "El habla”, en De camino al habla. Tr. Y. Zimmermann. Barcelona, SerbalGuitard, 1990, pp. 9-31.

MCLUHAN, M. La galaxia Gutenberg: Génesis del "homo typographicus". Tr. J. Novella. Barcelona, Galaxia Gutenberg, 1998. 